\title{
Cancer incidence, prevalence and survival in an aging Norwegian population
}

\author{
Astri Syse ${ }^{1}$, Marijke Veenstra ${ }^{1}$, Bjarte Aagnes $^{2}$ and Steinar Tretli ${ }^{2}$ \\ 1) Norwegian Social Research (NOVA) \\ 2) Cancer Registry of Norway \\ Correspondence: Astri Syse, NOVA, Postboks 3223 Elisenberg, NO-0208 Oslo, Norway \\ E-mail: astri.syse@nova.no Telephone: +47 47032304
}

\begin{abstract}
Background: Cancer is a disease closely associated with aging. Aging populations will thus lead to a pronounced increase in the absolute number of elderly persons with cancer, resulting in profound public health challenges in the coming decades. Older patients have distinct treatment and care needs, but are nevertheless largely overlooked in studies. We therefore examine cancer incidence, prevalence and survival among older cancer patients to help guide various stakeholders in the acute and more long-term handling of this patient group.

Data and methods: $>400000$ cancers diagnosed in individuals age 65+ in 1975-2009 were extracted from the Cancer Registry of Norway. Descriptive analyses of incidence and prevalence were undertaken, and survival analysis was used to model survival.

Results: The absolute number of elderly (65-79 years) and oldest old (80+ years) patients has more than doubled since 1975, and will continue to grow towards 2030. A more than threefold increase in patients $80+$ years has taken place. The largest patients groups comprise colorectal, prostate, lung and breast cancer. For all patients 65 and older, the median survival has increased with 135\%. The increase has been most pronounced for the elderly patients. Surgical resection rates decline with increasing patient age. The difference in relative survival is around 8 percentage points at three years $(60 \% \mathrm{vs} 52 \%)$. It has been constant over time. Conclusion: "Best practice" guidelines for the large and increasing group of older cancer patients remain to be established. The gain in length of lives must be balanced against patients' quality of life, and considered in a cost-benefit perspective for society at large.
\end{abstract}

\section{BACKGROUND}

Cancer is a disease strongly associated with aging, and the median age at diagnosis is close to 70 years in Norway (1). The increase in the number of elderly persons (2) together with stable and/or increasing cancer incidence rates $(1,3,4)$ will result in a pronounced increase in the absolute number of elderly persons with cancer and thus in need of treatment and long-term follow-up and care $(5,6)$. This will lead to significant public health challenges in the coming decades at a societal level in terms of the associated economic and noneconomic costs and at an individual level in terms of treatment and care needs.

The vast majority of clinical trials have stringent eligibility criteria for trial entry $(7,8)$, resulting in scarce inclusion of older patients. This has led to an inadequate understanding of appropriate treatment protocols for surgery, radiation and chemotherapy for older cancer patients, increasing with increasing patient age. It has further restricted the accessible knowledge of expected outcomes like for instance surgery-related complications and survival rates (9). Also patientreported outcomes such as fatigue, pain, nausea and quality of life are largely lacking for older patients (10). Relative to younger patients, older patients are on average less fit and have a greater number of other illnesses which may interfere with cancer treatment directly or indirectly $(6,11-14)$, confirmed by a recent review by Marengoni et al (15). Older cancer patients are more costly than younger patients as they require longer hospital stays and experience a higher number of treatment-related complications $(11,13,16-19)$. Older patients thus have distinctive needs in terms of diagnosis, treatment and care, but are nevertheless largely overlooked or excluded from studies due to challenges related to competing mortality or comorbidity $(5,7$, 13,14).

Some exceptions exist, however, and interest in geriatric oncology is emerging as population aging warrants more detailed knowledge of benefits and costs associated with treatment and care of older cancer patients $(13,17)$. A recent review underscores for instance the need to carefully consider who should be aggressively treated among those of high age due to the residual high risk of adverse outcomes (20). This is underscored by a Norwegian study from 2011 which shows that the use of a comprehensive geriatric assessment may be useful in predicting both short- and longer-term outcomes of surgery in the oldest old patients (21). A retrospective study of all nonagenarian patients treated in a US hospital over the last two decades found that although $88 \%$ of patients were given active treatment, the rate of treatment-related mortality was very low (22). On the other hand, the mean survival of treated patients was 1.7 years, down to around 
one year for advanced disease and up to barely two years for localized disease (ibid). Questions of treatment benefits versus costs, both economic and noneconomic, thus remain.

Also in registry-based research, there is a limited focus on the oldest patients. Commonly reported fiveyear relative survival may be of limited use for patients 80 years and older who have short remaining life expectancies. Short-term measures such as one- and three-year survival have been suggested to be more relevant, but are rarely published. Our aims are therefore to utilize high quality data from the Cancer Registry of Norway to provide an updated overview of time trends in incidence, prevalence, short- and longer-term all-cause and relative survival among the elderly and oldest old cancer patients in Norway. A secondary aim is to identify characteristics associated with survival that may be relevant for patients, health care personnel, care plans and clinical guidelines in the acute and more long-term disease management, which have become particularly relevant in light of the recently implemented Coordination reform (23).

\section{DATA AND METHODS}

\section{Data}

Data on all Norwegian cancer cases diagnosed at 65+ years in the period 1975-2009 were obtained from the Cancer Registry of Norway (CRN). Mandatory reporting from clinicians, pathologists, and death certificates from 1953 onwards ensures completeness and high quality data (24). The CRN is linked to the Central Population Registry which provides vital statistics on all cancer patients. It is also matched regularly to the Norwegian Patient Registry for additional quality assurance. The overall completeness for all age groups combined was estimated to be $99 \%$ for the period 2001-2005 (ibid). During this time, 94\% of the cases were morphologically verified (site-specific range 60100\%). Hematological malignancies (C90-95) and tumors of the central nervous system (C70-72) were most frequently underreported. The proportion of cancer cases with unknown primary site and records based on death certificate only (DCO) increases with increasing patient age (ibid). The accuracy and completeness of information on diagnosis (e.g. stage) and treatment (e.g. resection status) is thus likely falling with increasing patient age.

The method of diagnosis was defined as clinical, by imaging or biochemical analysis, histological verification, death certificate only (DCO) or autopsy and unknown. We defined surgery within the first course of treatment either as no surgery (including biopsy for diagnosis but not treatment), minor excisions or other resections with non-curative intents as non-curative surgery, major excisions with attempts at tumor removal as curative surgery or unknown, the latter including categories where surgery type is unknown but also those where it is unknown whether surgery actually was performed. Stage was defined as local, regional spread, distant spread, and unknown, the latter category also comprising cases where staging is not applicable. Cancers were grouped based on topography using the International Classification of Diseases, version 10 (ICD-10) (25). The categories were colorectal (C15$\mathrm{C} 20)$, prostate (C61), lung (C34), renal/bladder (C64$\mathrm{C} 68)$, female breast (C50), skin (C43-C44, basal cell carcinomas exempted), hematopoietic/lymphoid (C81C96), female gynecological (C51-C57), pancreatic (C25) and other cancers. The cancers were categorized as being either a first or subsequent primary cancer. Information on radiation, chemotherapeutic and hormonal treatment was largely missing and could not be reliably analyzed.

All cancers $(\mathrm{N}=443545)$ diagnosed in individuals age 65 and above $(\mathrm{N}=398$ 072) in 1975-2009 were included in the descriptive analyses of incidence. As some persons are diagnosed with more than one cancer form after age 65 , there is not a one-to-one relationship between the number of cancer cases and cancer patients. Site-specific analyses were undertaken for the largest groups; Colorectal, prostate, lung, renal, bladder, skin and breast cancer. These groups receive different treatments and have vastly varying outcomes in part due to the natural courses of the diseases but also due to variations in available treatment options.

Survival analyses were restricted to patients diagnosed with a first cancer at age 65 or above in 19752009 with a survival time greater than zero, excluding all cases diagnosed by death certificate only (DCO) or at autopsy $(\mathrm{N}=349683)$. All patients were followed from date of diagnosis to date of emigration, death or January 1 2012, whichever occurred first. Norwegian life tables by sex, one-year age group and one-year calendar period updated through 2009 were downloaded from the human mortality database website (26), and data for the years 2010 and 2011 were extrapolated from the year 2009 .

\section{Methods}

Cancer incidence, prevalence, all-cause and relative survival (excess mortality) among the elderly (65-79 years) and oldest old (80+ years) patients in Norway were examined. Analyses were undertaken to assess differences in cancer characteristics, diagnosis and treatment between the time periods 1975-1979, 19901994 and 2005-2008. Further analyses were carried out to provide an overview of the current (2009) annual cancer incidence burden. Descriptive statistics were used to examine demographic and diagnostic features of patients diagnosed after age 65 in the period 1975 2009 alive January 12012 ( $\mathrm{N}=66$ 754). The oldest old cancer survivors $(\mathrm{N}=41114)$ were examined specifically. The future cancer burden in terms of new cases and survivorship was predicted next, applying current cancer incidence and survival rates on projected populations (2).

All-cause survival by age group and diagnostic pe- 
Table 1. Age distribution of cancer cases diagnosed in individuals age 65 and over in 1975, 1992 and 2009.

\begin{tabular}{|c|c|c|c|c|c|}
\hline \multirow[b]{2}{*}{ Age at diagnosis } & $1975(\mathrm{~N}=7758)$ & \multicolumn{2}{|c|}{$1992(\mathrm{~N}=13076)$} & \multicolumn{2}{|c|}{$2009(N=17270)$} \\
\hline & $\mathbf{N}$ & $\mathbf{N}$ & $\%$ change $^{a}$ & $\mathbf{N}$ & \% change $^{a}$ \\
\hline $65-79$ years & 5634 & 8894 & 58 & 10663 & 89 \\
\hline $65-69$ & 1681 & 2373 & 41 & 3456 & 106 \\
\hline $70-74$ & 2073 & 3375 & 63 & 3664 & 77 \\
\hline $75-79$ & 1880 & 3146 & 67 & 3543 & 88 \\
\hline $80+$ years & 2124 & 4182 & 97 & 6607 & 211 \\
\hline $80-84$ & 1336 & 2485 & 86 & 3233 & 142 \\
\hline $85-89$ & 576 & 1258 & 118 & 2307 & 301 \\
\hline $90-94$ & 179 & 372 & 108 & 872 & 387 \\
\hline $95+$ & 33 & 67 & 103 & 195 & 491 \\
\hline
\end{tabular}

Percentwise change from 1975.

\begin{tabular}{|c|c|c|c|c|}
\hline & \multirow{2}{*}{$\begin{array}{c}\begin{array}{c}65-79 \text { years } \\
(\mathrm{N}=10663)\end{array} \\
\%\end{array}$} & \multirow{2}{*}{$\begin{array}{c}\begin{array}{c}80+\text { years } \\
(\mathrm{N}=6607)\end{array} \\
\% \\
\end{array}$} & \multicolumn{2}{|c|}{$\begin{array}{c}\text { Total } \\
(\mathrm{N}=17 \text { 270) }\end{array}$} \\
\hline & & & $\mathbf{N}$ & $\%$ \\
\hline Male & 60.5 & 49.6 & 9667 & 56.0 \\
\hline Female & 39.5 & 50.4 & 7603 & 44.0 \\
\hline Histologically verified & 96.5 & 80.4 & 15519 & 89.9 \\
\hline Diagnostic imaging only & 2.2 & 7.0 & 726 & 4.2 \\
\hline Clinical examination only & 0.5 & 1.8 & 179 & 1.0 \\
\hline DCO or autopsy & 0.8 & 10.6 & 840 & 4.9 \\
\hline Unknown & 0.0 & 0.1 & 6 & 0.0 \\
\hline No surgery & 42.9 & 42.5 & 7383 & 42.8 \\
\hline Non-curative surgery & 0.9 & 1.2 & 179 & 1.0 \\
\hline Curative surgery & 55.1 & 44.9 & 8790 & 50.9 \\
\hline Unknown & 1.0 & 11.4 & 918 & 5.3 \\
\hline Localized & 60.4 & 54.0 & 9973 & 57.7 \\
\hline Regional spread & 26.8 & 23.0 & 4359 & 25.2 \\
\hline Distant spread & 10.0 & 10.1 & 1736 & 10.1 \\
\hline Unknown spread & 2.8 & 12.9 & 1202 & 7.0 \\
\hline Colorectal & 18.4 & 21.6 & 3401 & 19.7 \\
\hline Prostate & 20.7 & 11.5 & 2916 & 16.9 \\
\hline Lung & 11.4 & 9.0 & 1800 & 10.4 \\
\hline Renal/bladder & 8.0 & 8.5 & 1424 & 8.2 \\
\hline Breast & 7.5 & 6.5 & 1226 & 7.1 \\
\hline Skin & 9.5 & 15.9 & 2094 & 12.1 \\
\hline Hematopoietic/lymphoid & 7.9 & 8.3 & 1394 & 8.1 \\
\hline Female gynecological & 4.7 & 4.2 & 775 & 4.5 \\
\hline Pancreatic & 2.4 & 3.6 & 506 & 2.9 \\
\hline Other/unknown & 9.4 & 10.9 & 1734 & 10.0 \\
\hline First cancer & 81.1 & 75.5 & 13604 & 78.8 \\
\hline Subsequent cancer & 18.9 & 24.5 & 3666 & 21.2 \\
\hline
\end{tabular}

riod was estimated using the Kaplan-Meier estimator. Relative survival (RS) for all cancer sites combined and for selected subsites was estimated by life table methods (27). RS is the ratio of the observed survival proportion to the expected survival proportion derived from national life tables. Flexible parametric RS models estimating excess mortality ratios (EMR) were applied to assess differences in net cancer survival related to age and diagnostic period, and to examine the impact of potentially influential covariates $(28,29)$. Covariates relating to patient, tumor, diagnostic workup and treatment were added in this order, and model selection was guided by minimizing the Bayesian Information Criterion (BIC) (30). Three time periods were considered: 1975-1989, 1990-1999 and $\geq 2000$.
All analyses were undertaken in Stata 12, and the programs strs and stpm 2 were used for life table and survival modeling, respectively. The statistical significance level was set at $5 \%$.

\section{RESULTS}

\section{Cancer incidence}

Changes in the age distributions of elderly and oldest old cancer patients from 1975 to 2009 are shown in Table 1. Patients were older and more numerous in 2009 compared to 1975 and more than 17000 patients 65 years and older are diagnosed with cancer on an annual basis today. The absolute number of elderly (65-79 years) and oldest old (80+ years) patients has more than doubled since 1975 . The increase has been largest in the oldest old group, where a more than threefold increase has taken place. Table 2 provides an overview of the characteristics of the oldest old patients diagnosed on an annual basis today.

The median age at diagnosis was 76 years for all cancer cases diagnosed after age 65 during the time period 1975-2009 (standard deviation (SD) 7 years). It has been fairly stable from 1975 to 2009 . During the entire time span 1975-2009, the proportion of cancers histologically verified was $84 \%$ overall, whereas $5 \%$ were diagnosed by imaging only. A total of $8 \%$ were confirmed only via death certificates (DCO) or autopsy. The percentage histologically verified declined sharply with age ( $88 \%$ for age $65-79$ vs $77 \%$ for $80+$ ), whereas the DCO and autopsy proportion increased ( $7 \%$ for age $65-79$ vs $10 \%$ for $80+$ ). More men than women were diagnosed with cancer between age 65 and 79 (58\% vs $42 \%)$, whereas the gender distribution was fairly equal after age 80 . Overall, $85 \%$ were first cancers, but the proportion declined with increasing patient age ( $87 \%$ for age $65-79$ vs $83 \%$ for $80+)$. $\mathrm{Cu}-$ rative surgery was performed on around half of all cancer cases, but it was lower for the patients age 80+ relative to those $65-79(45 \%$ vs $53 \%)$. The cancer report did not state whether or not surgery was performed in $8 \%$ of the cases, and this was related to age ( $6 \%$ for age $65-79$ vs $11 \%$ for $80+$ ). 
Table 3. Descriptive statistics of incident cancer cases in 1975-79, 1990-1994 and 2005-09.

\begin{tabular}{|c|c|c|c|c|c|c|}
\hline & \multicolumn{2}{|c|}{$1975-1979(N=41823$} & \multicolumn{2}{|c|}{$1990-1994(\mathrm{~N}=64910)$} & \multicolumn{2}{|c|}{$2005-2009(\mathrm{~N}=83557)$} \\
\hline & $65-79$ years & $80+$ years & $65-79$ years & $80+$ years & $65-70$ years & $80+$ years \\
\hline & $\mathrm{N}=29093$ & $\mathrm{~N}=12730$ & $\mathrm{~N}=43926$ & $\mathrm{~N}=20984$ & $\mathrm{~N}=48075$ & $\mathrm{~N}=35482$ \\
\hline & $\%$ & $\%$ & $\%$ & $\%$ & $\%$ & $\begin{array}{c}\% \\
503\end{array}$ \\
\hline $\begin{array}{l}\text { Male } \\
\text { Female }\end{array}$ & $\begin{array}{l}56.7 \\
43.3\end{array}$ & $\begin{array}{l}52.3 \\
47.7\end{array}$ & $\begin{array}{l}58.2 \\
41.8\end{array}$ & $\begin{array}{l}50.4 \\
49.6\end{array}$ & $\begin{array}{l}60.0 \\
40.0\end{array}$ & $\begin{array}{l}50.3 \\
49.7\end{array}$ \\
\hline Histologically verified & 76.8 & 66.0 & 88.5 & 78.3 & 95.4 & 80.9 \\
\hline Diagnostic imaging only & 3.4 & 6.3 & 2.9 & 6.9 & 2.9 & 8.6 \\
\hline Clinical examination only & 4.3 & 10.5 & 1.0 & 3.7 & 0.6 & 2.5 \\
\hline DCO or autopsy & 15.5 & 17.3 & 7.6 & 11.1 & 1.0 & 8.0 \\
\hline Localized & 54.1 & 54.2 & 56.0 & 55.3 & 46.2 & 39.6 \\
\hline Regional spread & 15.3 & 12.8 & 21.3 & 16.3 & 25.5 & 23.3 \\
\hline Distant spread & 27.3 & 23.6 & 15.0 & 13.3 & 11.5 & 11.4 \\
\hline Unknown spread & 3.4 & 9.4 & 7.7 & 15.1 & 16.8 & 25.8 \\
\hline Colorectal & 23.9 & 28.1 & 22.1 & 24.5 & 18.4 & 21.8 \\
\hline Prostate & 14.2 & 16.2 & 15.1 & 15.8 & 20.7 & 12.8 \\
\hline Lung & 8.4 & 3.8 & 10.8 & 5.2 & 11.5 & 8.5 \\
\hline Renal/bladder+A43 & 8.9 & 7.4 & 9.7 & 8.2 & 8.3 & 8.2 \\
\hline Breast cancer & 9.0 & 7.8 & 8.0 & 8.5 & 7.3 & 6.8 \\
\hline Skin cancer & 3.8 & 6.4 & 7.4 & 10.6 & 9.1 & 14.9 \\
\hline Hematopoietic/lymphoid & 7.4 & 7.3 & 6.6 & 6.7 & 7.6 & 8.0 \\
\hline Female gynecological & 6.3 & 4.3 & 5.4 & 4.5 & 4.7 & 4.3 \\
\hline Pancreatic & 4.1 & 3.7 & 3.3 & 3.9 & 2.5 & 3.7 \\
\hline Other/unknown & 14.0 & 15.0 & 11.6 & 12.1 & 9.8 & 11.0 \\
\hline First cancer & 93.6 & 92.5 & 86.8 & 84.9 & 82.0 & 76.1 \\
\hline Subsequent cancer & 6.4 & 7.5 & 13.2 & 15.1 & 18.0 & 23.9 \\
\hline No surgery & 40.1 & 48.2 & 25.7 & 23.9 & 42.9 & 43.8 \\
\hline Non-curative surgery & 5.7 & 6.3 & 11.7 & 16.3 & 1.3 & 1.7 \\
\hline Curative surgery & 53.1 & 42.5 & 57.1 & 48.4 & 55.1 & 46.4 \\
\hline Unknown & 1.1 & 3.0 & 5.5 & 11.4 & 0.7 & 8.2 \\
\hline
\end{tabular}

A detailed description of cancer incidence for patients age 65 and above at diagnosis for an early, middle and late time period (1975-79, 1990-94 and 2005-09, respectively) is shown in Table 3. Overall, there has been an increase in the proportion of oldest old cancer cases that are histologically verified (from $66 \%$ to $81 \%$ ), and a similar reduction in the proportion diagnosed based on DCO or autopsy (from $17 \%$ to $8 \%$ ), but the trend is not very different from that observed for those 65-79 years old. The proportions diagnosed in local stages were fairly similar for the elderly and oldest old patients in earlier time periods. It has declined for all patients in the latest time period, but more so for the oldest old than the elderly ( $40 \%$ versus $46 \%$ ), which may be attributed to an increased use of more advanced diagnostic equipment and tests. Due to changes in the coding practices at CRN, the proportion of patients with an unknown stage at diagnosis has risen sharply from the earliest time period to the latest time period. The pattern of change is, however, not very different for the elderly and the oldest old patients. The most common malignancies diagnosed in the oldest old today are colorectal (22\%), skin $(15 \%)$, prostate $(13 \%)$, lung $(9 \%)$ and renal/bladder $(8 \%)$, and the distribution is not very different from that observed among elderly patients. The proportion of subsequent cancers is higher in the oldest old than in the elderly for all time periods, and it has increased over time (from $8 \%$ in the earliest time period to $24 \%$ today) with important implications for treatment and cancer care. The oldest old patients receive curative surgery less often than younger cancer patients, with likely survival implications, but the difference has been relatively stable, around 10 percentage points, over time.

The age-specific incidence rates have been fairly stable for the high age groups over the last decade $(1,3)$, with the exception of breast and prostate cancer where the uptake of screening is evolving also at higher ages $(31,32)$. When we apply the current incidence rates to Statistics Norway's high life expectancy projected population 80 years and above for 2020, 2030 and 2040 (2), we find that the annual number of oldest old patients will increase only slightly up until 2020, whereas this age group will grow very fast from this point onwards. Up until 2030, the number of cancer cases diagnosed at age 80 or above will increase by about $70 \%$, resulting in around 11450 cancer diagnoses annually. Likewise, the increase up until 2040 will be around $140 \%$, resulting in 15700 cancer diagnoses annually in this age group.

\section{Cancer prevalence}

Concurrent with an increasing number of individuals being diagnosed with cancer in older ages, survival has increased over time for both younger and older patients. Cancer survivorship has thus become an issue also in relatively high ages. As can be seen from Table 4, in 2011 more than 41000 of the oldest old persons were living with a 2-year history of cancer diagnosed 

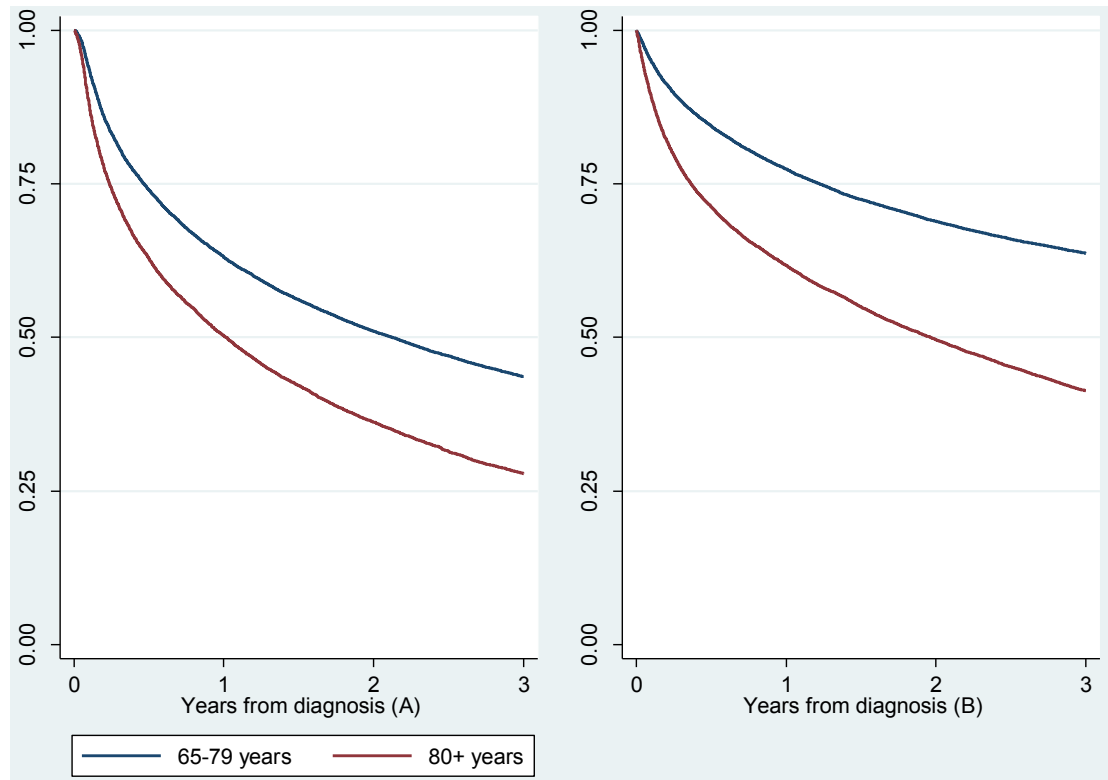

Figure 1. All-cause three-year survival by age below or above 80 at diagnosis, for patients diagnosed in 1975-79 (A) vs 2005-08 (B). Patients diagnosed in 2009 were not included as they had a maximum follow-up time of only two years.

Table 4. Descriptive statistics of cancer survivors 80 years and older per January 2012, alive for minimum 2 years post-diagnosis $(\mathrm{N}=41114){ }^{a}$

\begin{tabular}{|c|c|c|}
\hline & \multicolumn{2}{|c|}{ Cancer survivors } \\
\hline & $\mathbf{N}$ & $\%$ \\
\hline Male & 19780 & 48.1 \\
\hline Female & 21334 & 51.9 \\
\hline Diagnostic year 1975-89 & 923 & 2.2 \\
\hline Diagnostic year 1990-99 & 10573 & 25.7 \\
\hline Diagnostic year 2000-09 & 29618 & 72.0 \\
\hline $65-74$ years at diagnosis & 15424 & 37.5 \\
\hline $75-84$ years at diagnosis & 21405 & 52.1 \\
\hline $85+$ years at diagnosis & 4285 & 10.4 \\
\hline Histologically verified & 40254 & 97.9 \\
\hline Diagnostic imaging only & 730 & 1.8 \\
\hline Clinical examination only & 116 & 0.3 \\
\hline Unknown & 14 & 0.0 \\
\hline No surgery & 9672 & 23.5 \\
\hline Non-curative surgery & 162 & 0.4 \\
\hline Curative surgery & 30910 & 75.2 \\
\hline Unknown resection status & 370 & 0.9 \\
\hline Colorectal cancer & 8886 & 21.6 \\
\hline Prostate cancer & 7736 & 18.8 \\
\hline Skin cancer & 7362 & 17.9 \\
\hline Breast cancer & 5323 & 12.9 \\
\hline Renal/bladder cancer & 4021 & 9.8 \\
\hline Female gynecological cancer & 2420 & 5.9 \\
\hline Hematopoietic/lymphoid cancer & 2021 & 4.9 \\
\hline Lung cancer & 564 & 1.4 \\
\hline Pancreatic cancer & 52 & 0.1 \\
\hline Other/unknown cancer & 2729 & 6.6 \\
\hline First cancer & 36360 & 88.4 \\
\hline Subsequent cancer & 4754 & 11.6 \\
\hline Localized & 24253 & 59.0 \\
\hline Regional spread & 7333 & 17.8 \\
\hline Distant spread & 737 & 1.8 \\
\hline Unknown spread & 8791 & 21.4 \\
\hline
\end{tabular}

in the period 1975-2009 after age 65, and the oldest person was 111 years old. The actual number of cancer survivors above 80 years of age is higher, as those recently diagnosed (i.e. during 2010 and 2011) could not be included due to data limitations. For the same reason, long-time survivors diagnosed before age 65 and/or before 1975 could not be included. Cancer survivors diagnosed in the period 1975-89 comprise, however, only $2 \%$ of the group and the latter exclusion is thus likely to matter very little.

Colorectal, prostate and breast cancer survivors are most prevalent in the population, and more than $97 \%$ had a histologically verified cancer. The majority of the 2-year survivors were between 75 and 84 years old at diagnosis $(52 \%)$, and more than $75 \%$ had received curative surgery.

When we apply the current age-specific incidence rates and the current survival rates to the aforementioned future predicted populations, the estimated number of cancers diagnosed in individuals 80 years and older will be around 71000 in 2030 and nearly 100000 in 2040.

\section{All-cause survival (Observed mortality)}

Altogether, we observed 337524 deaths of any cause during the maximum 36 year follow-up period (85\%). A total of 222151 persons died within three years (56\%). All-cause three-year survival decreases substantially with increasing age, but has improved considerably from $1975-79$ to 2005-08 (Figure 1). The median survival time for elderly patients diagnosed in 1975-79 was 2.1 years (95\% confidence interval (CI) 2.0-2.2), 3.2 years (CI 3.1-3.3) in 1990-94, whereas it could not be calculated for those diagnosed in 2005-08. For the oldest old patients, the corresponding survival times were 1.0 (CI 1.0-1.1), 1.4 (CI 1.3-1.4) and 2.0 years 
Table 5. Life table relative survival estimates (\%) with $95 \%$ confidence intervals for all cancers and selected cancer forms by age at diagnosis and diagnostic period. ${ }^{a}$

\begin{tabular}{|c|c|c|c|c|c|c|}
\hline & \multicolumn{3}{|c|}{$65-79$ years } & \multicolumn{3}{|c|}{$80+$ years } \\
\hline & 1-year & 3-year & 5-year & 1-year & 3-year & 5-year \\
\hline All cancers ${ }^{\mathrm{b}}$ & $73(72-73)$ & $60(59-60)$ & $54(54-54)$ & $64(64-64)$ & $52(52-53)$ & $47(47-48)$ \\
\hline 1975-79 & $66(65-66)$ & $50(49-51)$ & $44(43-44)$ & $58(57-59)$ & $43(42-45)$ & $38(37-40)$ \\
\hline $1990-94$ & $72(71-72)$ & $58(57-58)$ & $52(51-53)$ & $64(63-65)$ & $51(50-53)$ & $45(44-47)$ \\
\hline 2005-08 & $79(79-80)$ & $69(69-70)$ & $65(64-65)$ & $69(68-70)$ & $59(58-60)$ & $55(54-56)$ \\
\hline Colorectal cancer $^{b}$ & $69(68-69)$ & $53(52-53)$ & $47(47-48)$ & $58(57-58)$ & $45(44-46)$ & $42(41-43)$ \\
\hline $1975-79$ & $56(55-58)$ & $39(38-41)$ & $35(33-36)$ & $45(43-47)$ & $29(27-31)$ & $25(23-28)$ \\
\hline $1990-94$ & $68(67-69)$ & $53(51-54)$ & $47(46-49)$ & $56(54-58)$ & $42(40-44)$ & $39(37-41)$ \\
\hline 2005-08 & $77(76-78)$ & $64(62-65)$ & $58(57-60)$ & $66(64-67)$ & $55(53-57)$ & $53(50-56)$ \\
\hline Prostate cancer ${ }^{\mathrm{b}}$ & $95(94-95)$ & $85(85-86)$ & $76(76-77)$ & $89(89-90)$ & $74(73-75)$ & $62(61-63)$ \\
\hline $1975-79$ & $90(89-91)$ & $71(69-73)$ & $59(56-61)$ & $81(78-83)$ & $61(57-64)$ & $50(45-54)$ \\
\hline $1990-94$ & $94(94-95)$ & $80(79-81)$ & $69(68-71)$ & $87(85-89)$ & $71(68-74)$ & $56(52-60)$ \\
\hline 2005-08 & $99(99-100)$ & $96(96-97)$ & $94(92-95)$ & $94(92-96)$ & $85(82-88)$ & $77(73-81)$ \\
\hline Lung cancer $^{\mathrm{b}}$ & $34(33-35)$ & $14(13-15)$ & $10(9-10)$ & $23(22-24)$ & $7(6-8)$ & $4(3-5)$ \\
\hline 1975-79 & $32(30-35)$ & $10(9-12)$ & $7(6-9)$ & $22(17-28)$ & $6(3-11)$ & $4(1-8)$ \\
\hline $1990-94$ & $32(30-34)$ & $13(12-14)$ & $9(8-10)$ & $20(16-23)$ & $5(4-8)$ & $3(2-6)$ \\
\hline 2005-08 & $39(37-40)$ & $18(17-19)$ & $13(12-15)$ & $25(23-28)$ & $8(7-10)$ & $4(3-6)$ \\
\hline Renal/bladder cancer ${ }^{\mathrm{b}}$ & $83(82-84)$ & $71(70-72)$ & $65(64-66)$ & $71(70-72)$ & $60(58-62)$ & $55(53-57)$ \\
\hline $1975-79$ & $79(77-81)$ & $64(62-67)$ & $57(55-59)$ & $66(61-70)$ & $53(47-58)$ & $47(41-54)$ \\
\hline $1990-94$ & $83(81-84)$ & $71(70-73)$ & $65(63-67)$ & $72(69-75)$ & $60(56-65)$ & $54(49-59)$ \\
\hline 2005-08 & $86(84-87)$ & $76(74-78)$ & $72(69-74)$ & $76(74-79)$ & $68(64-71)$ & $65(60-70)$ \\
\hline Skin cancer ${ }^{b}$ & $97(97-97)$ & $92(92-93)$ & $89(88-90)$ & $97(96-97)$ & $90(89-91)$ & $88(86-90)$ \\
\hline $1975-79$ & $96(94-98)$ & $90(87-92)$ & $84(80-88)$ & $94(90-97)$ & $87(81-93)$ & $87(78-95)$ \\
\hline $1990-94$ & $97(95-98)$ & $92(90-94)$ & $90(88-92)$ & 98 (96-99) & $92(89-96)$ & $89(83-94)$ \\
\hline 2005-08 & $98(97-99)$ & $94(93-96)$ & $91(89-93)$ & $98(96-99)$ & $95(92-97)$ & $91(87-95)$ \\
\hline Female breast cancer ${ }^{b}$ & $96(95-96)$ & $87(86-88)$ & $81(80-82)$ & $91(90-92)$ & $81(80-83)$ & $74(72-76)$ \\
\hline $1975-79$ & $93(92-94)$ & $80(78-82)$ & $71(69-74)$ & $88(85-91)$ & $75(70-80)$ & $67(61-74)$ \\
\hline $1990-94$ & $95(94-96)$ & $87(86-89)$ & $80(78-82)$ & $91(88-93)$ & $80(76-83)$ & $72(68-77)$ \\
\hline 2005-08 & $97(96-98)$ & $92(90-93)$ & $89(87-90)$ & $93(91-95)$ & $83(80-86)$ & $81(76-86)$ \\
\hline
\end{tabular}

(CI 1.9-2.2), respectively. For all patients 65 and older, the median survival has increased from 1.7 years (CI $1.6-1.7$ ) in $1975-79$ to 4.0 (CI 3.9-4.0) years in 2005 08 , corresponding to a $135 \%$ increase.

\section{Relative survival (Excess mortality)}

Life table estimates are portrayed in Table 5 and show that age is an important prognostic factor. Although survival has increased over time, the difference between the elderly and the oldest old has been fairly constant over time: The three-year RS difference for all cancer forms combined was $16 \%$ for the earliest (50\% vs $43 \%)$ and the latest (69\% vs 59\%) time period when comparing those 65-79 years old with those $80+$. The mortality selection was most pronounced during the first year, and appeared to decline more gradually from this point onwards. RS was fairly good after skin, prostate and breast cancer, whereas it was very poor after lung cancer, for all age groups. The largest percent wise difference in three-year RS between the age groups was observed for lung cancer (18\% vs $8 \%$ ), whereas no age difference was observed for skin cancer (94\% vs 95\%). For colorectal, prostate, breast, renal and bladder cancer, the differences were $16 \%$, $13 \%, 11 \%$ and $12 \%$, respectively.
We observe improvements in RS from 1975 to today for many of the prevalent cancer forms, for both elderly and oldest old patients. For the latter group, the three-year RS changes have been most pronounced for colorectal cancer (from $29 \%$ to $55 \%$ ), prostate cancer (from $61 \%$ to $85 \%$ ) and for renal and bladder cancer (from 53\% to 68\%). There has been virtually no change in the RS after lung cancer, and the improvements after skin and breast cancer have been minor.

Excess mortality ratios from RS models are shown in Table 6. According to model C, survival was $32 \%$ worse for the oldest old patients compared to the elderly, and it was also $11 \%$ worse for men compared to women. Compared to those diagnosed in the 1970 s and $1980 \mathrm{~s}$, a $19 \%$ increase in survival was observed for patients diagnosed during the last decade. No improvement was, however, observed for the patients diagnosed in the 1990s. Cancer form was included primarily as a control variable, and the results were in line with what is previously known. Also the effects of stage were as predicted, with two- to fourfold worse survival outcomes for more advanced stages. Survival is $37 \%$ better for patients with histologically verified cancers. Curative surgery is the factor most strongly associated with prolonged survival, and having recei- 
Table 6. Excess mortality ratios from three relative survival models examining the influence of covariates on excess mortality. ${ }^{a}$

\begin{tabular}{|c|c|c|c|c|c|c|}
\hline & \multicolumn{2}{|c|}{ Model A } & \multicolumn{2}{|c|}{ Model B } & \multicolumn{2}{|c|}{ Model C } \\
\hline & EMR $^{\mathrm{b}}$ & $95 \% \mathrm{Cl}^{\mathrm{C}}$ & EMR & $95 \% \mathrm{Cl}$ & EMR & $95 \% \mathrm{Cl}$ \\
\hline \multicolumn{7}{|l|}{ Age at diagnosis } \\
\hline $65-79$ years & 1 & & 1 & & 1 & \\
\hline $80+$ years & 1.42 & $1.40-1.44$ & 1.39 & $1.37-1.41$ & 1.32 & $1.30-1.34$ \\
\hline \multicolumn{7}{|l|}{ Gender } \\
\hline Female & 1 & & 1 & & 1 & \\
\hline male & 1.02 & $1.01-1.03$ & 1.11 & $1.10-1.13$ & 1.11 & $1.09-1.12$ \\
\hline \multicolumn{7}{|l|}{ Year of diagnosis } \\
\hline 1975-89 & 1 & & 1 & & 1 & \\
\hline 1990-99 & 0.84 & $0.83-0.85$ & 0.94 & $0.93-0.96$ & 1.03 & $1.02-1.05$ \\
\hline$\geq 2000$ & 0.68 & $0.67-0.69$ & 0.73 & $0.72-0.74$ & 0.81 & $0.80-0.82$ \\
\hline \multicolumn{7}{|l|}{ Cancer form } \\
\hline Other/unknown & & & 1 & & 1 & \\
\hline Colorectal & & & 0.68 & $0.67-0.69$ & 1.02 & $0.99-1.04$ \\
\hline Prostate & & & 0.20 & $0.20-0.21$ & 0.18 & $0.18-0.19$ \\
\hline Lung & & & 1.62 & $1.59-1.65$ & 1.37 & $1.34-1.39$ \\
\hline Renal/bladder & & & 0.55 & $0.53-0.56$ & 0.76 & $0.74-0.78$ \\
\hline Breast & & & 0.24 & $0.23-0.25$ & 0.37 & $0.36-0.39$ \\
\hline Skin & & & 0.14 & $0.14-0.15$ & 0.23 & $0.22-0.24$ \\
\hline Hematopoietic/lymphoid & & & 1.69 & $1.65-1.73$ & 1.04 & $1.02-1.07$ \\
\hline Female gynecological & & & 0.50 & $0.49-0.52$ & 0.65 & $0.65-0.67$ \\
\hline Pancreatic cancer & & & 2.00 & $1.95-2.05$ & 1.83 & $1.78-1.87$ \\
\hline \multicolumn{7}{|l|}{ Stage at diagnosis } \\
\hline Localized & & & 1 & & 1 & \\
\hline Regional spread & & & 2.36 & $2.32-2.41$ & 2.27 & 2.23-2.31 \\
\hline Distant spread & & & 6.04 & $5.95-6.15$ & 4.40 & $4.33-4.47$ \\
\hline Unknown spread & & & 2.04 & $2.00-2.09$ & 1.69 & $1.65-1.73$ \\
\hline \multicolumn{7}{|l|}{ Diagnostic basis } \\
\hline Not histologically verified ${ }^{d}$ & & & 1 & & 1 & \\
\hline Histologically verified & & & 0.45 & $0.45-0.46$ & 0.63 & $0.62-0.64$ \\
\hline \multicolumn{7}{|l|}{ Resection status } \\
\hline No curative surgery ${ }^{d}$ & & & & & 1 & \\
\hline Curative surgery & & & & & 0.27 & $0.27-0.28$ \\
\hline \multicolumn{7}{|l|}{ Model diagnostics } \\
\hline Log likelihood (model) & \multicolumn{2}{|c|}{-570859} & \multicolumn{2}{|c|}{-498433} & \multicolumn{2}{|c|}{-485968} \\
\hline $\mathrm{BIC}$ & \multirow{2}{*}{\multicolumn{2}{|c|}{1141871}} & \multicolumn{2}{|c|}{997186} & \multicolumn{2}{|c|}{972294} \\
\hline Degrees of freedom & & & \multicolumn{2}{|c|}{25} & \multicolumn{2}{|c|}{28} \\
\hline
\end{tabular}

Estimates from flexible parametric models (Stata command:stpm2) with 5 degrees of freedom for main effects and 2 degrees of freedom for time-dependent effects. Spline parameters for the underlying hazard are not shown (available upon request). Age at diagosis (all models) and resection status (model C) were modeled as time-dependent effects and were statistically significant at the $p<0.01$ level (not shown, available upon request). The final model is shown to the far right. ${ }^{b}$ Excess mortality ratio. ${ }^{\circ}$ Confidence interval. ${ }^{d}$ Includes also those with missing status.

ved curative surgery improved survival by around $70 \%$. Due to the relatively good prognosis of skin cancer, the models in Table 6 were also set up excluding all skin cancer cases. The results remained, however, virtually identical. Models were also run excluding cancer form, but also here the results remained quite similar (available upon request).

Analyses stratified on the six most common cancer forms are shown in Table 7 . The excess mortality associated with being 80 years and older was most pronounced for prostate cancer $(52 \%)$, followed by renal and bladder cancer $(35 \%)$ and lung cancer $(30 \%)$. The effect of old age was least manifest for breast cancer (20\%). Women had a 9\% survival disadvantage after renal and bladder cancer relative to men, whereas the excess mortality for men was $48 \%$ for skin, $16 \%$ for colorectal and $12 \%$ for lung cancer. An improvement in survival from the earliest time period to the $1990 \mathrm{~s}$ was observed only for breast and prostate cancer
(EMR 0.80 and 0.82 , respectively). Improvement to the latest time period was observed for all cancer forms, skin and lung exempted. The improvement was greatest for prostate cancer, followed by breast, renal and bladder, and colorectal cancers. Curative surgery was the strongest predictor for survival after lung, colorectal and breast cancer.

Table 8 shows excess mortality ratios separately for elderly and oldest old patients. In general, the importance of most covariates appeared to be fairly similar across the two groups. Curative surgery was the strongest predictor for excess mortality in all age groups, but somewhat more important for the oldest old (EMR 0.22 vs 0.30 ). The improvement in survival from the earliest to the latest time period was, however, somewhat more pronounced for the elderly compared to the oldest old (EMR 0.78 vs 0.88 ). Cancers with distant spread resulted in worse outcomes for the elderly compared to the oldest old (EMR 5.09 vs 3.22). 
Table 7. Excess mortality ratios from relative survival models stratified on common cancer forms. ${ }^{a}$

\begin{tabular}{|c|c|c|c|c|c|c|c|c|c|c|c|c|}
\hline & \multicolumn{2}{|c|}{ Colorectal } & \multicolumn{2}{|r|}{ Lung } & \multicolumn{2}{|c|}{ Renal/bladder } & \multicolumn{2}{|r|}{ Skin } & \multicolumn{2}{|c|}{ Prostate } & \multicolumn{2}{|c|}{ Breast } \\
\hline & $\mathrm{EMR}^{\mathrm{b}}$ & $95 \% \mathrm{Cl}^{\mathrm{C}}$ & EMR & $95 \% \mathrm{Cl}$ & EMR & $95 \% \mathrm{Cl}$ & EMR & $95 \% \mathrm{Cl}$ & EMR & $95 \% \mathrm{Cl}$ & EMR & $95 \% \mathrm{Cl}$ \\
\hline \multicolumn{13}{|l|}{ Age at diagnosis } \\
\hline $65-79$ years & 1 & & 1 & & 1 & & 1 & & 1 & & 1 & \\
\hline $80+$ years & 1.28 & $1.25-1.32$ & 1.30 & $1.25-1.35$ & 1.35 & $1.27-1.43$ & 1.26 & $1.09-1.46$ & 1.52 & $1.45-1.60$ & 1.20 & $1.11-1.30$ \\
\hline \multicolumn{13}{|l|}{ Gender } \\
\hline Female & 1 & & 1 & & 1 & & 1 & & N/A & & N/A & \\
\hline male & 1.16 & $1.13-1.18$ & 1.12 & $1.09-1.15$ & 0.91 & $0.87-0.95$ & 1.48 & $1.32-1.66$ & & & & \\
\hline \multicolumn{13}{|l|}{ Year of diagnosis } \\
\hline $1975-89$ & 1 & & 1 & & 1 & & 1 & & 1 & & 1 & \\
\hline $1990-99$ & 1.13 & $1.09-1.16$ & 1.12 & $1.08-1.16$ & 1.04 & $0.99-1.10$ & 1.08 & $0.93-1.25$ & 0.82 & $0.79-0.86$ & 0.80 & $0.74-0.86$ \\
\hline$\geq 2000$ & 0.87 & $0.85-0.89$ & 0.99 & $0.96-1.02$ & 0.84 & $0.79-0.89$ & 1.03 & $0.89-1.19$ & 0.42 & $0.39-0.44$ & 0.71 & $0.66-0.77$ \\
\hline \multicolumn{13}{|l|}{ Stage at diagnosis } \\
\hline Localized & 1 & & 1 & & 1 & & 1 & & 1 & & 1 & \\
\hline Regional spread & 2.24 & $2.18-2.31$ & 1.40 & $1.35-1.45$ & 4.48 & $4.22-4.76$ & 13.13 & $11.13-15.47$ & 2.26 & $2.06-2.48$ & 3.02 & $2.77-3.30$ \\
\hline Distant spread & 3.89 & $3.76-4.03$ & 2.46 & $2.37-2.55$ & 8.07 & $7.57-8.62$ & 26.58 & $22.67-31.15$ & 5.71 & $5.43-6.01$ & 8.54 & $7.82-9.32$ \\
\hline Unknown spread & 1.71 & $1.64-1.79$ & 1.20 & $1.14-1.26$ & 1.90 & $1.77-2.05$ & 1.12 & 0.89-1.41 & 1.21 & $1.12-1.30$ & 1.68 & $1.54-1.84$ \\
\hline \multicolumn{13}{|l|}{ Diagnostic basis } \\
\hline Not histologically verified ${ }^{d}$ & 1 & & 1 & & 1 & & 1 & & 1 & & 1 & \\
\hline Histologically verified & 0.63 & $0.61-0.66$ & 0.70 & $0.67-0.23$ & 0.57 & $0.54-0.62$ & 0.24 & $0.15-0.37$ & 0.64 & $0.46-0.52$ & 0.51 & $0.45-0.57$ \\
\hline \multicolumn{13}{|l|}{ Resection status } \\
\hline No curative surgery ${ }^{d}$ & 1 & & 1 & & 1 & & 1 & & 1 & & 1 & \\
\hline Curative surgery & 0.22 & $0.22-0.23$ & 0.21 & $0.19-0.23$ & 0.49 & $0.47-0.53$ & 0.97 & $0.83-1.13$ & 0.64 & $0.60-0.68$ & 0.31 & $0.29-0.34$ \\
\hline
\end{tabular}

\section{DISCUSSION}

We have illustrated the pronounced changes that have taken place in incidence, prevalence and survival for the oldest old patients over the last thirty to forty years, and shown that these changes will become even more prominent over the next twenty to thirty years as population aging accelerates. An increase in the number of patients aged 80 and above from a little over 2000 in 1975 to around 16000 in 2040 will necessarily draw resources, both economic and non-economic, from an already strained public health care sector. According to a recent report on future hospital needs in Norway, the expected increase in the number of persons $70+$ will by year 2030 demand 1.5 million additional hospital days per year which amounts to almost 5000 additional hospital beds (33). This corresponds to a nearly $50 \%$ increase in the number of beds available nationally in 2009, roughly six to seven hospitals the size of the Ullevaal division of Oslo University Hospital in Norway (ibid). Likewise will the future handling of more than 100000 cancer survivors 80 years and older require a restructuring of services. The latter estimate is likely a gross underestimate, as the survival rates have improved markedly over the last decades and are likely to continue improving in the near future. The recently implemented Coordination reform focuses on health care organization in aging populations and attempts to minimize costs by moving a larger part of services from specialist to primary care (23), but will necessitate vaster resources directed also to the primary care sector.
Consensus recommendations and national guidelines have traditionally primarily focused on younger patients due to the lack of clinical data on treatment benefits as well as adverse effects in the oldest old patient groups. With the current population aging, the attention is to a larger extent expanded to include the oldest old patients. A revised national cancer strategy will be released towards the end of 2012 focusing on capacity, quality and organization of treatment and care to help ensure that future challenges will be met in a comprehensive manner (34), hopefully diverting attention also to the oldest old patients in terms of the proposed focus on transitions of services between different care levels and long-term effects. The proposed time perspective is, however, relatively short as the main focus is directed to the years 2013-2017 (ibid). In terms of personnel, equipment, and appropriate facilities such as nursing homes and community living units, such a short time perspective may be insufficient. Similarly, the observed increase in survival documented also for the oldest old patients will have implications for longterm survivorship follow-up of individuals in their $80 \mathrm{~s}$, $90 \mathrm{~s}$ and 100s. As adverse short-term and long-term effects of the disease itself as well as treatment are more prevalent at older ages, this will need to be taken into consideration in future cancer strategies and plans.

\section{Diagnosis and treatment of elderly and oldest old patients}

Due to improvements in early diagnosis and screening, particularly for prostate and breast cancer $(32,35)$, some of the improvement in survival observed over time 
Table 8. Excess mortality ratios from relative survival models stratified on age at diagnosis. ${ }^{a}$

\begin{tabular}{|c|c|c|c|c|}
\hline & \multicolumn{2}{|c|}{$65-79$ years } & \multicolumn{2}{|c|}{80 years and older } \\
\hline & $E \mathbf{R}^{\mathrm{b}}$ & $95 \% \mathrm{Cl}^{\mathrm{C}}$ & EMR & $95 \% \mathrm{Cl}$ \\
\hline \multicolumn{5}{|l|}{ Gender } \\
\hline Female & 1 & & 1 & \\
\hline Male & 1.11 & $1.10-1.13$ & 1.09 & $1.07-1.11$ \\
\hline \multicolumn{5}{|l|}{ Year of diagnosis } \\
\hline $1975-89$ & 1 & & 1 & \\
\hline 1990-99 & 1.02 & $1.01-1.04$ & 1.05 & $1.02-1.07$ \\
\hline$\geq 2000$ & 0.78 & $0.77-0.79$ & 0.88 & $0.85-0.90$ \\
\hline \multicolumn{5}{|l|}{ Cancer form } \\
\hline Other/unknown & 1 & & 1 & \\
\hline Colorectal & 0.97 & $0.95-0.99$ & 1.08 & $1.05-1.11$ \\
\hline Prostate & 0.18 & $0.18-0.19$ & 1.19 & $0.18-0.20$ \\
\hline Lung & 1.42 & $1.39-1.45$ & 1.15 & $1.11-1.20$ \\
\hline Renal/bladder & 0.75 & $0.73-0.78$ & 0.75 & $0.72-0.78$ \\
\hline Breast & 0.40 & $0.38-0.41$ & 0.31 & $0.29-0.33$ \\
\hline Skin cancer & 0.25 & $0.23-0.26$ & 0.18 & $0.15-0.20$ \\
\hline Hematopoietic/lymphoid & 1.05 & $1.02-1.09$ & 1.03 & 0.99-1.07 \\
\hline Female gynecological & 0.60 & $0.58-0.62$ & 0.76 & $0.73-0.80$ \\
\hline Pancreatic & 1.96 & $1.90-2.02$ & 1.53 & $1.47-1.60$ \\
\hline \multicolumn{5}{|l|}{ Stage at diagnosis } \\
\hline Localized & 1 & & 1 & \\
\hline Regional spread & 2.46 & $2.41-2.51$ & 1.96 & $1.90-2.02$ \\
\hline Distant spread & 5.09 & $4.99-5.20$ & 3.22 & $3.12-3.32$ \\
\hline Unknown spread & 1.71 & $1.66-1.75$ & 1.56 & $1.51-1.61$ \\
\hline \multicolumn{5}{|l|}{ Diagnostic basis } \\
\hline Not histologically verified ${ }^{d}$ & 1 & & 1 & \\
\hline Histologically verified & 0.60 & $0.59-0.62$ & 0.65 & $0.63-0.66$ \\
\hline \multicolumn{5}{|l|}{ Resection status } \\
\hline No curative surgery ${ }^{d}$ & 1 & & 1 & \\
\hline Curative surgery & 0.30 & $0.29-0.31$ & 0.22 & $0.22-0.23$ \\
\hline \multicolumn{5}{|l|}{ Model diagnostics } \\
\hline Log likelihood (model) & \multicolumn{2}{|c|}{-361930} & \multicolumn{2}{|c|}{-123202} \\
\hline $\mathrm{BIC}$ & \multicolumn{2}{|c|}{723910} & \multicolumn{2}{|c|}{246696} \\
\hline Degrees of freedom & \multicolumn{2}{|c|}{25} & \multicolumn{2}{|c|}{25} \\
\hline \multicolumn{5}{|c|}{$\begin{array}{l}\text { a Estimates from flexible parametric models (Stata command:stpm2) stratified by age with } 5 \text { degrees of } \\
\text { freedom for main effects and } 2 \text { degrees of freedom for the time-dependent effect. Spline parameters for the } \\
\text { underlying hazard are not shown (available upon request). Resection status was modeled as a time- } \\
\text { dependent effect and was statistically significant at the } p<0.01 \text { level (not shown, available upon request). } \\
\text { bexcess mortality ratios. }{ }^{\circ} \text { Confidence interval. }{ }^{d} \text { Includes also those with missing status. }\end{array}$} \\
\hline
\end{tabular}

might be a result of lead time bias, with individuals living longer with a known diagnosis but not necessarily having a real implication for the time of death. The degree to which screening continues to be used with increasing age and how screening during middle or older age affects survival in the oldest old remains, however, a topic for discussion $(35,36)$, and it is not clear how to interpret the observed findings on the changes over time by age in the survival after breast and prostate cancer.

We found that the oldest old patients receive histological verification of their diagnosis to a lesser extent than older patients. In earlier days, this was often thought to be reflective of less aggressive treatment plans. With improvements in clinical imaging tools, patients with cancers which are not histologically verified may still be handled appropriately. This might be reflected also in this study as the effect of histological verification is quite similar across age groups although the selection is much greater among the oldest old.

Today's complex cancer therapy regimens may be more difficult for the oldest old patients to follow, and health care interventions directed and adapted more specifically to this broad subgroup might be warranted $(37,38)$. Surgery remains the primary mode of curative treatment for cancer but resection rates decrease with increasing patient age, as is observed also in this study. The main reason being increased risks of peri- and postoperative adverse events, which are consistently documented to be much more frequent in the oldest old patients $(12,13)$, even though there is a strongly selected group of "fit" oldest old patients who receive surgery (22). Despite the strong selection, the oldest old are more expensive to treat overall compared to younger patients. This is mostly due to the average length of hospital stays being longer and the higher 
number of admittances due to postoperative complications $(15,18)$. In line with this, we observe the largest age differences in survival outcomes after lung cancer which are difficult to operate on, whereas there is hardly any difference after skin cancer requiring less extensive surgery. At the same time, there have been few improvements over time for these cancer forms, while rather large improvements for the oldest old have been seen after colorectal, prostate, renal and bladder cancer. Surprisingly, the modeled improvements in survival are only statistically significant for the latest time period. When stratifying on age above and below 80 years at diagnosis, we see that the effect of covariates tend to be very similar, although the change over time has been more pronounced for the elderly than the oldest old patients. Curative resection is a stronger predictor for advantageous survival among the oldest old, whereas advanced stage leads to worse consequences for the elderly compared to the oldest old patients. For the most prevalent cancer forms, we see that curative resection is particularly important for lung, colorectal and breast cancer. Skin cancer is less invasive and treatment is generally less aggressive. We thus expected lesser age differences between elderly and oldest old patients for this cancer form. Surprisingly, this was in general not observed. Neither did the overall estimates change when skin cancer was excluded from the analyses.

To summarize, relatively withstanding low curative surgery rates and pronounced complication rates in the oldest old cancer patients have resulted in a greater percent wise survival increase for the younger elderly patients. The optimal use of chemotherapy and radiation in a curative perspective is currently debated in older patients, and assessment scales, guidelines and protocols are slowly developing as evidence continues to emerge (38-42). As we only have information on surgery, benefits and risks associated with chemotherapy or radiation is not further discussed.

\section{Methodological considerations, limitations and future research needs}

The validity and completeness of data on the oldest old patients remains a problem both for research purposes and for the patients themselves as "good" treatment requires adequate diagnosis and treatment. Furthermore, the influence of competing causes of death, both in the registration procedures and as a methodological problem in the analyses arise in studying the impact of cancer in the elderly and oldest old (27). Competing causes of death analyses will need to complement our study to ensure adequate interpretations of studies that consider changes in cancer incidence and prognosis among the very old.

Norway is a supposedly egalitarian society with free public health available to all citizens, both young and old. At the same time, the public health care system attempts to minimize costs and thus demands fairly strict evidence for the implementation of newly avai- lable surgical or pharmaceutical treatment regimens (see e.g. http://oncolex.no for a list of available drugs in Norway), compared to for instance in the US where the reimbursement system promotes treatment of both very ill and very old patients (43). Norway nevertheless generally performs well in more general international comparisons of cancer survival, but these analyses are generally limited to individuals below age $75(3,44)$. Detailed studies on outcomes cross-nationally after cancer in the oldest old are largely lacking.

At an individual level, knowledge of treatment options and expected outcomes are important for persons with cancer and their next of kin to ensure that they receive optimal treatment and care, and more so today than previously with greater demands of patients making informed choices in discussions with providers $(45,46)$. Such information is also of utmost relevance for those who are responsible for, in a broad sense, aiding cancer patients. Whether or not the elderly and oldest old cancer patients are appropriately handled in the health care system or treated disadvantageously due to their high age is not obvious today. The lack of specific guidelines accounting for individual characteristics of patients, such as biological and physiological age, comorbidities, mental health status, prescription mediation, social support and living situation, means that many medical decisions are made on an individual basis by individual health care providers or teams. Both overtreatment and undertreatment is likely to occur, with consequences for resource utilization in terms of for instance time and treatment costs at a societal level and adverse effects at an individual level in terms of reduced survival or multiple negative sideeffects of cancer treatment. One solution could be to accumulate a knowledge base available to the larger medical community to draw experience from, which could aid clinicians in deciding not to treat patients due to poor outcome and/or high costs, and to adequately interpret findings from cancer studies concerned with quality and costs during diagnosis, treatment, and long-term follow-up. One recent suggestion entails utilizing measures of patients' likely remaining life expectancies to help clinicians and patients balance treatment burdens with expected gains in remaining length of lives (47).

\section{CONCLUSION}

We have provided an indication of the current cancer burden in the elderly and oldest old population in Norway, and shed light on the pronounced changes that have occurred over the last thirty to forty years. We have also presented coarse estimates of future changes that are likely to take place. Aging populations and stable or increasing cancer incidence and survival rates have resulted in a pronounced increase in the absolute number of elderly persons with (a history of) cancer in need of treatment and long-term follow-up and care, and this increase is expected to 
continue, particularly strongly from 2030 onwards. This will in turn lead to profound public health challenges in the coming decades, as older patients and survivors have distinctive needs in dealing with adverse short-term and long-term effects of the disease itself as well as the treatment. Nevertheless, "best practice" guidelines for specific age and comorbidity segments of the oldest old population remain to be established. Discussions relating to the balance between gains in lengths of lives and patients' quality of life viewed in terms of a cost-benefit perspective for society at large will likely emerge.

\section{REFERENCES}

1. Cancer Registry of Norway. Cancer in Norway 2010. Available from http://www.kreftregisteret.no/Global/ Cancer\%20in\%20Norway/CIN_2010_with_Special_Issue_clustering_of_cancer_web.pdf. 2012 October 3 [cited 2012 Oct 5].

2. Statistics Norway. Norway's population. Available from http://statbank.ssb.no/statistikkbanken/. 2012 June 6 [cited 2012 Jun 6].

3. Ferlay S, Shin HR, Bray F, Foreman D, Mathers C, Parkin DM. GLOBOCAN 2008 v1.2, Cancer Incidence and Mortality Worldwide: IARC CancerBase No. 10. Available from http:/globocan.iarc.fr. 2010 July 6 [cited 2012 May 5].

4. Møller B, Aagnes B. Cancer in Norway 2005. Predictions of cancer incidence by health region 2010-2020. Available from http://www.kreftregisteret.no/Global/Publikasjoner\%20og\%20rapporter/CiN2005_del2 web.pdf. 2006.

5. Muss HB. Cancer in the elderly: a societal perspective from the United States. Clin Oncol (R Coll Radiol) 2009 Mar; 21 (2): 92-8.

6. Dale W, Mohile SG, Eldadah BA, Trimble EL, Schilsky RL, Cohen HJ, et al. Biological, clinical, and psychosocial correlates at the interface of cancer and aging research. J Natl Cancer Inst 2012; 104 (8): 581-9.

7. Hutchins LF, Unger JM, Crowley JJ, Coltman CA, Albain KS. Underrepresentation of patients 65 years of age or older in cancer-treatment trials. $N$ Engl J Med 1999; 341 (Special Issue): 2061-7.

8. National Cancer Institute. Overcoming age limits in cancer clinical trials. Available from http://www.cancer. gov/ncicancerbulletin/051810/page8. 2010 May 18 [cited 2012 Jun 7].

9. Mohile S, Dale W, Hurria A. Geriatric oncology research to improve clinical care. Nat Rev Clin Oncol 2012; 9 (10): 571-8.

10. Sanoff HK, Goldberg RM, Pignone MP. A systematic review of the use of quality of life measures in colorectal cancer research with attention to outcomes in elderly patients. Clin Colorectal Cancer 2007; 6 (10): 700-9.

11. Robb C, Boulware D, Overcash J, Extermann M. Patterns of care and survival in cancer patients with cognitive impairment. Crit Rev Oncol Hematol 2010; 74 (3): 218-24.

12. Janssen-Heijnen ML, Maas HA, Houterman S, Lemmens VE, Rutten HJ, Coebergh JW. Comorbidity in older surgical cancer patients: influence on patient care and outcome. Eur J Cancer 2007; 43 (15): 2179-93.

13. Kowdley GC, Merchant N, Richardson JP, Somerville J, Gorospe M, Cunningham SC. Cancer surgery in the elderly. ScientificWorldJournal 2012; 2012: 303852.

14. Ritchie CS, Kvale E, Fisch MJ. Multimorbidity: an issue of growing importance for oncologists. $J$ Oncol Pract 2011; 7 (6): 371-4.

15. Marengoni A, Angleman S, Melis R, Mangialasche F, Karp A, Garmen A, et al. Aging with multimorbidity: a systematic review of the literature. Ageing Res Rev 2011; 10 (4): 430-9.

16. Wright JD, Lewin SN, Barrena Medel NI, Sun X, Burke WM, Deutsch I, et al. Morbidity and mortality of surgery for endometrial cancer in the oldest old. Am J Obstet Gynecol 2011; 205 (1): 66-8.

17. Damhuis RA, Meurs CJ, Meijer WS. Postoperative mortality after cancer surgery in octogenarians and nonagenarians: results from a series of 5,390 patients. World J Surg Oncol 2005; 3: 71.

18. Al-Refaie WB, Parsons HM, Habermann EB, Kwaan M, Spencer MP, Henderson WG, et al. Operative outcomes beyond 30-day mortality: colorectal cancer surgery in oldest old. Ann Surg 2011; 253 (5): $947-52$.

19. Yabroff KR, Lamont EB, Mariotto A, Warren J, Topor M, Meekins A, et al. Cost of care for elderly cancer patients in the United States. J Natl Cancer Inst 2008; 100: 630-41.

20. van Leeuwen BL, Kristjansson SR, Audisio RA. Should specialized oncogeriatric surgeons operate older unfit cancer patients? Eur J Surg Oncol 2010; 36 (Suppl 1): S18-S22.

21. Kristjansson SR, Nesbakken A, Jordhoy MS, Skovlund E, Audisio RA, Johannessen HO, et al. Comprehensive geriatric assessment can predict complications in elderly patients after elective surgery for colorectal cancer: a prospective observational cohort study. Crit Rev Oncol Hematol 2010; 76 (3): 208-17.

22. Extermann M, Crane EJ, Boulware D. Cancer in nonagenarians: profile, treatments and outcomes. Crit Rev Oncol Hematol 2010; 75 (2): 160-4. 
23. Norwegian Ministry of Health and Care Services. Summary in English: Report No. 47 (2008-2009) to the Storting. The Coordination Reform. Proper treatment - at the right place and the right time. Available from http://www.regjeringen.no/en/dep/hod/kampanjer/the-coordination-reform/annet/the-coordinationreform.html?id=669079. 2009 [cited 2012 May 6].

24. Larsen IK, Smastuen M, Johannesen TB, Langmark F, Parkin DM, Bray F, et al. Data quality at the Cancer Registry of Norway: an overview of comparability, completeness, validity and timeliness. Eur J Cancer 2009; 45 (7): 1218-31.

25. World Health Organization. ICD-10 classification scheme. Available from http://apps.who.int/classifications/ icd10/browse/2010/en\#/II. 2010 [cited 2012 Jun 6].

26. University of California \& Max Planck Institute. Human Mortality Database. Available from http://www. mortality.org/. 2012 [cited 2012 May 5].

27. Dickman PW, Adami HO. Interpreting trends in cancer patient survival. J Intern Med 2006; 260 (2): $103-17$.

28. Lambert PC, Royston P. Further development of flexible parametric models for survival analysis. The Stata Journal 2009; 9 (2): 265-90.

29. Rutherford MJ, Dickman PW, Lambert PC. Comparison of methods for calculating relative survival in population-based studies. Cancer Epidemiol 2012; 36 (1): 16-21.

30. Schwarz GE. Estimating the dimension of a model. Annals of Statistics 1978; 6 (2): 461-4.

31. Crivellari D, Aapro M, Leonard R, von MG, Brain E, Goldhirsch A, et al. Breast cancer in the elderly. $J$ Clin Oncol 2007; 25 (14): 1882-90.

32. Quon H, Loblaw A, Nam R. Dramatic increase in prostate cancer cases by 2021. BJU Int 2011; 108 (11): 1734-8.

33. Petersen SO. Fremskrivning av behovet for sykehustjenester. Metode og resultater for 2020 og 2030 [in Norwegian]. Trondheim, Norway: Helsetjenesteforskning. SINTEF Helse, 2011. Report No. E.

34. Ministry of Health and Social Affairs. Ny nasjonal kreftplan [in Norwegian]. Available from http://www. regjeringen.no/nb/dep/hod/pressesenter/pressemeldinger/2012/ny-nasjonal-kreftstrategi.html?id=672688. 2012 [cited 2012 Jun 6].

35. Mandelblatt JS, Schechter CB, Yabroff KR, Lawrence W, Dignam J, Extermann M, et al. Toward optimal screening strategies for older women. Costs, benefits, and harms of breast cancer screening by age, biology, and health status. J Gen Intern Med 2005; 20 (6): 487-96.

36. Jerant AF, Franks P, Jackson JE, Doescher MP. Age-related disparities in cancer screening: analysis of 2001 Behavioral Risk Factor Surveillance System data. Ann Fam Med 2004; 2 (5): 481-7.

37. Extermann M. Geriatric oncology: an overview of progresses and challenges. Cancer Res Treat $2010 ; 42$ (2): 61-8.

38. Droz JP, Aapro M, Balducci L. Overcoming challenges associated with chemotherapy treatment in the senior adult population. Crit Rev Oncol Hematol 2008; 68 (Suppl 1): S1-S8.

39. Pasetto LM, Basso U, Friso ML, Pucciarelli S, Agostini M, Rugge M, et al. Determining therapeutic approaches in the elderly with rectal cancer. Drugs Aging 2007; 24 (9): 781-90.

40. Balducci L. Aging, frailty, and chemotherapy. Cancer Control 2007; 14 (1): 7-12.

41. Extermann M, Boler I, Reich RR, Lyman GH, Brown RH, Defelice J, et al. Predicting the risk of chemotherapy toxicity in older patients: The Chemotherapy Risk Assessment Scale for High-Age Patients (CRASH) score. Cancer 2012; 118 (13): 3377-86.

42. Houterman S, Janssen-Heijnen ML, Verheij CD, Kil PJ, van den Berg HA, Coebergh JW. Greater influence of age than co-morbidity on primary treatment and complications of prostate cancer patients: an in-depth population-based study. Prostate Cancer Prostatic Dis 2006; 9 (2): 179-84.

43. Meropol NJ, Schulman KA. Cost of cancer care: issues and implications. J Clin Oncol 2007; 25 (2): $180-6$.

44. Engholm G, Kejs AM, Brewster DH, Gaard M, Holmberg L, Hartley R, et al. Colorectal cancer survival in the Nordic countries and the United Kingdom: excess mortality risk analysis of 5 year relative period survival in the period 1999 to 2000. Int J Cancer 2007; 121 (5): 1115-22.

45. Puts MT, Hardt J, Monette J, Girre V, Springall E, Alibhai SM. Use of geriatric assessment for older adults in the oncology setting: a systematic review. J Natl Cancer Inst 2012; 104 (15): 1134-64.

46. Elkin EB, Kim SH, Casper ES, Kissane DW, Schrag D. Desire for information and involvement in treatment decisions: elderly cancer patients' preferences and their physicians' perceptions. J Clin Oncol 2007; 25 (33): 5275-80.

47. Hoffe S, Balducci L. Cancer and age: general considerations. Clin Geriatr Med 2012; 28 (1): 1-18. 